\title{
PERCEPÇÕES DO ALUNO DE CURSO SUPERIOR NA MODALIDADE EAD SOBRE SUA TRAJETÓRIA DE APRENDIZAGEM
}

\author{
CURITIBA/PR MAIO/2018
}

\author{
Marilene Santana dos Santos Garcia ～- UNINTER - marilene.g@uninter.com \\ Willian Rufato da Silva - UNINTER - willianrufato@hotmail.com \\ Jaqueline Becker - UNINTER - jaque.becker@yahoo.com.br \\ Vanda Fattori Dias - UNINTER - vandafattori@uol.com.br
}

Tipo: Investigação Científica (IC)

Natureza: Descrição de Projeto em Andamento

Categoria: Pesquisa e Avaliação

Setor Educacional: EDUCAÇÃO SUPERIOR

\begin{abstract}
RESUMO
O artigo objetiva levantar alguns aspectos sobre a percepção dos alunos de cursos superiores a distância quanto à sua trajetória educacional, refletindo sobre seu processo de resiliência no enfrentamento de desafios, que implicam condições internas e externas ao curso, afetando sua permanência ou desistência do curso, a manutenção do foco, a gestão desse processo de estudos para atingir sua meta de conclusão. A pesquisa partiu de 2 hipóteses: 1) os alunos de cursos superiores a distância são resilientes e enfrentam dificuldades pessoais e sociais, tendo como objetivo o alcance do diploma; 2) esses alunos consideram o impacto positivo na vida profissional como uma das maiores razões para continuar estudando a distância. Como suporte teórico foram trabalhados autores Reis (2015); Martin-Barbiero (2012); Kenski (2012); Oliveira et al. (2012); Catapan et al.(2010) entre outros. A metodologia privilegiou o levantamento de dados empíricos, utilizando um questionário estruturado, com perguntas fechadas, algumas com alternativas, que foi aplicado a 26 estudantes de ensino superior. Os resultados preliminares, a partir de uma abordagem qualitativa, apontam para a confirmação das hipóteses aventadas, porém revelando algumas discrepâncias dos relatos dos respondentes sobre as percepções apuradas
\end{abstract}

Palavras-chave: Educação a distãncia; ensino superior; percepções dos alunos de EAD

\section{AGRADECIMENTOS}

AO CENTRO UNIVERSITÁRIO INTERNACIONAL - UNINTER - PELO INESTIMÁVEL APOIO ÀS PESQUISAS E À PARTICIPAÇÃO EM EVENTOS DE EAD. 


\section{Introdução}

A EaD ao longo desses últimos anos, por consequência da alta inserção de tecnologia, revela-se como uma modalidade de ensino que interfere diretamente nas possibilidades de realização pessoal e profissional de uma parte população que se sentia excluída do sonho de finalizar um curso superior. Isso, entre outras razões, deve-se às legislações que começaram a viabilizar variedades nos níveis de oferta de cursos.

Contudo, existem muitos questionamentos e controvérsias sobre a qualidade da formação desse público nessa modalidade de estudos, e que devem ser consideradas como parte desta construção social. Segundo Reis (2015, p. 2):

\footnotetext{
Apesar de diversas controvérsias sobre a efetividade do EAD, percebe-se uma vertente muito forte que defende $O$ EAD como uma forma de inclusão social. Esta modalidade de ensino tem sido apontada como favorável por criar possibilidades para amenizar a desigualdade social e oportunizar a atualização profissional de muitas pessoas, permitindo que estas tenham acesso a diferentes tipos de conhecimento.
}

A metodologia desse estudo privilegiou a pesquisa empírica, com a aplicação de questionários a 26 alunos para levantar sua percepção sobre o processo de fazer um curso superior em EaD. As hipóteses levantadas foram de certa forma confirmadas, mas também sinalizaram um viés de percepção sobre como a EaD afeta esses sujeitos, instituindo contradições ou dificuldade no registro da realidade desses alunos.

\section{Leis que apoiam cursos superiores em EaD no Brasil}

O Art. 80 da Lei de Diretrizes e Bases da Educação (LDB), № 9.394, de 20/12/1996, autorizou os cursos de EaD no Brasil, com sua primeira atualização a partir do Decreto nº 5.622, de 19/12/2005 e segunda atualização, com o decreto número 9.057/2017.

A partir deste decreto, as instituições de ensino superior tiveram a permissão de ofertar cursos superiores de graduação e pós-graduação a distância, com seus próprios polos de EaD, sem a exigência de credenciamento prévio na modalidade presencial, o que antes era exigência.

O crescimento da oferta de cursos superiores em EaD é incontestável. O Censo realizado pelo INEP[1] em 2015 sobre a Educação Superior levantou que no Brasil havia 1.473 mil cursos superiores a distância. Segundo dados do portal do MEC (2017), há mais de 1,3 milhão de estudantes matriculados, com crescimento de $50 \%$ entre os anos de 2010 e 2015. 


\section{Considerações teóricas}

A EaD expandiu-se no Brasil com um forte significado social, pois abarca diferentes níveis de ensino, com experimentações metodológicas inovadoras, formas de avaliação e tutorias, embasados, principalmente, por três fatores: i) a inserção de tecnologias de comunicação, informação e interativas digitais; ii) novas leis e decretos; iii) necessidade de atender à alta demanda de estudantes buscando o diploma de nível superior.

Deste modo, a EaD atual pode ser vista como um resultado de uma revolução tecnológica que afeta formas de produção, formação e linguagens, como evidenciam Martín-Barbero (2014, p.66):

\footnotetext{
Além da evidente transformação dos meios técnico, a revolução tecnológica produz transformações transversais que evidenciam a emergência de um ecossistema educativo conformado não só por novas máquinas ou meios, mas por novas linguagens, escritas e saberes, pela hegemonia da experiência audiovisual sobre a tipográfica e a reintegração da imagem ao campo da produção de conhecimento.
}

Os recursos empregados nos cursos em ambientes virtuais de aprendizagem visam se aproximar de seus alunos, gerando ganhos tanto quantitativos quanto qualitativos, mesmo assim faz-se necessário superar diferentes formas de distância. Um exemplo são as disparidades tecnológicas, principalmente de conexão, que inviabilizam acessos e domínio de competências para o emprego de TICs em projetos educacionais (KENSKI, 2012). Outro exemplo refere-se à distância social, somada à desconfiança e ao preconceito com que essa modalidade de formação ainda é vista.

Aspectos ligados à resiliência e permanência no curso superior em EaD relacionam-se também à evasão, podendo ser definitiva ou provisória, ou seja, por cancelamento ou transferência. Para Oliveira et al. (2012), estudos que analisam o fracasso escolar originam-se de duas abordagens: $1^{a}$ ) as que buscam entendem os fatores que estão externos à escola, abrangendo, entre outros aspectos as demandas do mundo do trabalho; as desigualdades sociais, as responsabilidades do estudante com referência à família, vida social etc.; $\left.2^{\circ}\right)$ estudos que tratam de fatores internos, associados principalmente ao fracasso escolar, à proposta pedagógica-didática da própria escola, a relações e linguagens utilizadas entre alunos e professores, o formato e a qualidade do material didático, dentre outros fatores.

Estes aspectos inter-relacionam-se com as condições de permanência ou abandono do curso pelos estudantes de EaD, sendo dinâmicos e fluídos, interferindo nas tomadas de decisão ao longo do curso. 


\section{Dados e discussão}

O grupo de respondentes desta pesquisa foi composto de 26 pessoas alunos de cursos superiores em EaD, com o seguinte perfil: $54 \%$ do sexo masculino e $46 \%$ do sexo femininoe e faixa etária de 18 a 51 anos, sendo que 57\% deles estão entre 18 e 34 anos. O estado civil dos respondentes corresponde a $42 \%$ de casados e a $54 \%$ de solteiros, os demais $4 \%$ declaram-se "outros".

Sobre o tempo que ficaram sem estudar após concluir o ensino médio do nível básico, a maioria, representada por $46 \%$ ficou mais de quadro anos sem estudar. Esse fator evidencia o valor da EAD em resgatar interessados em prosseguir os estudos. Quando perguntados se consideram o conteúdo do curso adequado, 100\% dos respondentes afirmaram que sim, mostrando, porém, algumas discrepâncias em comentários extras à referida pergunta, conforme mostra o quadro 1.

Quadro 1 - Comentários extras dos respondentes sobre a adequação do conteúdo do curso.

\begin{tabular}{|l|l|}
\hline Respondentes & Comentários extras sobre a adequação do conteúdo \\
\hline Comentário 1 & Porém deixa a desejar em alguns aspectos \\
\hline Comentário 2 & Um pouco difícil, mas está adequado \\
\hline Comentário 3 & Tenho obtido bom conhecimento \\
\hline Comentário 4 & Em questão ao conteúdo aplicado em curso, estou satisfeita \\
\hline Comentário 5 & Mais ou menos \\
\hline
\end{tabular}

Fonte: os próprios autores

Os referidos comentários abrem-se para dois tipos de interpretação. O primeiro é de que os conteúdos são vistos como adequados, o segundo é de que os respondentes demonstram desconforto com os conteúdos, apresentando um pensamento crítico sobre eles: "deixa a desejar", "mais ou menos", o que ainda não representam uma crítica em si, mas apenas indícios de que algo não está satisfatório.

A frequência de acesso ao AVA[2], semanalmente, também foi questionada, sendo que as respostas sinalizam para um contato frequente semanal com o AVA, posto que ninguém declarou não acessá-lo, com a predominância de 5 a 10 acessos (46\%) e na Contudo, isso não pode sinalizar ainda que um menor acesso represente uma menor dedicação aos estudos, podendo sinalizar para uma postura pontuada e regrada desse aluno. 
Quando perguntados sobre a qualidade do material didático disponibilizado no AVA, utilizado nos cursos, foram dadas as seguintes respostas, conforme mostra a tabela 1:

Tabela 1 : Qualidade de material didático

\begin{tabular}{|l|l|l|}
\hline Respostas & $\begin{array}{l}\text { Número } \\
\text { respondentes }\end{array}$ & de \\
\hline Satisfatório & 9 & $35 \%$ \\
\hline Regular & 15 & $58 \%$ \\
\hline Insatisfatório & 2 & $8 \%$ \\
\hline TOTAL & 26 & $100 \%$ \\
\hline
\end{tabular}

Fonte: os próprios autores

Essa avaliação foi bastante positiva, com predominância do conceito regular (58\%), frente ao satisfatório (35\%), o que sinaliza para uma pequena discrepância de opinião quando confrontada com a questão levantada sobre a adequação do material didático, em que $100 \%$ avaliou como boa. Destes $8 \%$ afirmam estar insatisfeitos, o que ainda não chega caracterizar grande discrepância em relação à outras avaliações positivas sobre este quesito. Somente um respondente reinvidica a oferta de mais material na forma de exercícios.

Ao serem perguntados sobre o tempo que se dedicam aos estudos a distância, utilizando os materiais disponíveis, constata-se a realidade desses alunos a distância quanto à gestão do tempo para os estudos semanais, visto que $65 \%$ dos respondentes dedicam-se mais de 10 horas e $35 \%$ dedicam-se de 10 a vinte 20 horas, nenhum dos respondentes tem dedicação acima de 20 horas semanais.

Um outro fator preponderente em estudos a distância é a interação, por meio da comunicação com o tutor, realizada de diversas formas, conforme releva a tabela 2 .

Tabela 2 - Comunicação com o tutor

\begin{tabular}{|l|l|l|}
\hline Respostas & $\begin{array}{l}\text { Número de } \% \\
\text { respondentes }\end{array}$ & \\
\hline Utilizar o fórum & 8 & $23 \%$ \\
\hline Usar o polo para estudos & 15 & $43 \%$ \\
\hline Usar Whatsapp & 6 & $17 \%$ \\
\hline Usar E-Mail & 6 & $17 \%$ \\
\hline & &
\end{tabular}


\begin{tabular}{l|l|l|} 
TOTAL & 35 & $100 \%$ \\
\hline
\end{tabular}

Fonte: os próprios autores

Nesse caso, a preponderência de $43 \%$ dos casos está no uso dos polos[3] para os estudos, lugar em que a figura do tutor é consultada presencialmente, já $23 \%$ utilizam o AVA e $17 \%$ utilizam respectivamente o e-mail e o Whatsapp. Esse fator chama a atenção com relação aos estudos a longo prazo, que devem garantir uma interação mais direta nos polos pelo contato com o tutor, enfatizando a necessidade de ocupar este espaço. Logo, trata-se de mais um indício sobre o gerenciamento do tempo, que implica distribuí-lo entre os estudos a distância e deslocamento para o polo.

Quando perguntados sobre as dificuldades enfrentadas nos estudos em EAD[4], as maiores dificuldades declaradas no decorrer dos estudos de EaD relacionam-se ao esclarecimento de dúvidas, com $41 \%$, em segundo lugar vem a dificuldade de estudar sozinho, com $34 \%$ e $24 \%$ dos respondentes dizem não ter dificuldades em estudar em $\mathrm{EaD}$ e nenhum respondente avaliou ter dificuldade em utilizar a internet. Sobre o esclarecimento de dúvidas constata-se que as instituições provedoras da EaD pressupõem que os alunos já estejam preparados para esta modalidade, contudo ainda precisam preparar os alunos, provendo formas de organização e gestão do tempo, explicação sobre a interface de acesso e seus conteúdos, formas avaliativas, como usar a tutoria, como postar os trabalhos e utilizar de forma mais eficaz os materiais disponíveis, entre outros fatores.

O dado que chamou a atenção relaciona-se aos $24 \%$ que afirmaram não enfrentar dificuldades em EaD, levando a duas interpretações iniciais: i) provavelmente esses respondentes não manifestaram sua opinião verdadeira de que enfrentam de fato dificuldades; ii) respondentes falam a verdade, porém não conseguem enxergar ou expressar as dificuldade que enfrentam em EaD. Entretanto, entende-se como mais plausível a segunda interpretação, pois foram feitos comentários espontâneos sobre as dificuldades, com viés de posicionamento dos respondentes, segundo mostra o quadro 2.

\section{Quadro 2 - Comentários espontâneos sobre as dificuldades}

\begin{tabular}{|l|l|}
\hline Número do comentário & Conteúdo do comentário \\
\hline Comentário 1 & Às vezes não consigo entender só vendo os vídeos \\
\hline Comentário 2 & Não ter professor para tirar dúvida \\
\hline Comentário 3 & Antes as vìdeo-aulas davam para entender melhor \\
\hline
\end{tabular}


Fonte: os próprios autores

Esses comentários, embora desprovidos de contextualização mais detalhada, desvendam situações de desconforto e dificuldade dos aprendizes on-line que não sustentam a afirmação de que não existe dificuldade EaD. Procurou-se levantar quais os fatores influenciavam os estudos, focando aspectos emocionais, didáticos e pedagógicos, segundo mostra a tabela 3[6].

Tabela 3: Fatores influenciadores do estudo: aspectos emocionais, didáticos e pedagógicos

\begin{tabular}{|l|l|l|}
\hline Respostas & $\begin{array}{l}\text { Número de } \\
\text { respondentes }\end{array}$ & \\
\hline Motivação & 8 & $26 \%$ \\
\hline Aprender a aprender & 6 & $18 \%$ \\
\hline Sucesso & 4 & $12 \%$ \\
\hline Afetividade & 2 & $6 \%$ \\
\hline Todas acima & 12 & $35 \%$ \\
\hline Outra & 1 & $3 \%$ \\
\hline TOTAL & 34 & $100 \%$ \\
\hline
\end{tabular}

Fonte: os próprios autores

Considerando-se cada item individualmente, constata-se que a motivação é o fator que mais influencia, segundo $26 \%$ dos respondentes; na sequência vem "aprender a aprender", depois "busca de sucesso profissional" com 12\% e a "afetividade", chama a atenção, visto que os respondentes declaram não se importar muito com ela. Contudo, sob o ponto de vista geral, $35 \%$ dos respondentes consideram esse conjunto de opções influenciam emocionalmente seus estudos.

Quando perguntados sobre suas características de perfil resiliente, de enfrentar e superar dificuldades ao longo do curso, a maior frequência de resposta está na superação de obstáculos, com $30 \%$ e na sequência, com $19 \%$, está a adaptação à mudança, em último lugar, com $4 \%$ está a capacidade de resistir à pressão de situações. $\mathrm{Na}$ perspectiva geral, todas estas afirmativas podem qualificar as características do perfil resiliente do aluno de EAD. Sobre indicar cursos de EAD a outras pessoas, $96 \%$ dos respondentes afirmaram "sim" e somente $4 \%$ "não". Foram perguntados sobre os motivos que os levam a indicar um curso em EaD, segundo o 
quadro 4.

\section{Quadro 4- Motivos para indicar cursos EAD}

\begin{tabular}{|l|}
\hline Menor custo com comodidade \\
\hline Flexibilidade de horário \\
\hline O curso de EAD corresponde ao curso normal presencial \\
\hline Os tutores, profissionais da área, contribuem ainda mais para o nosso \\
aprendizado. \\
\hline E também os professores colocam-se à disposição para solucionar as nossas \\
dúvidas \\
\hline Disponibilidade de tempo \\
\hline É um ensino prático de qualidade \\
\hline Somente aquelas que não possuem grande disponibilidadede tempo, pois ainda é \\
preferível o estudo preferencial \\
\hline Indicaria, pois de certa forma auxilia muito em alguns aspectos \\
\hline É uma ótima opção par quem trabalha e estuda \\
\hline Nunca é tarde para estudar \\
\hline É uma ótima opção para quem trabalha e estuda \\
\hline Há muitas pessoas que trabalham e estudam e seus horários são incompatíveis \\
com os deuma escola tradicional \\
\hline
\end{tabular}

Fonte: os próprios autores

As respostas mostram uma forma de considerar os benefícios da $\mathrm{EaD}$, extraídos pela experiência própria. As visões são bastante positivas, necessitando de uma reflexão mais profunda sobre as trajetos envolvida. Porém, os comentários complementares espontâneos enfatizam uma posição mais realista dos respondentes, de que o curso superior em EaD: 1) ampliou as possibilidades de trabalho; motivou para fazer outros cursos; 2)interferiu na qualidade de vida e na dinâmica familiar; 3) interferiu nas atividades de lazer.

\section{Considerações finais}

A análise qualitativa dos dados levantados confirma a primeira hipótese, de que esses alunos de cursos superiores em EaD enfrentam dificuldades pessoais e sociais, tendo como meta de alcance do diploma superior, porém não conseguem perceber ou expressar sobre suas dificuldades, embora sejam resilientes e enfrentem dificuldades, sem uma clara consciência desta. A segunda hipótese foi parcialmente confirmada, pois 
os alunos veem a EaD como oportunidade, para o alcance de uma nova chance profissional, contudo ainda este não conseguem discernir sobre como esta forma de oportunidade se configura no enfrentamento de como estudar, de como assimilar e contruir conhecimento.

O estudo constatou que requisitos pedagógicos e tecnológicos implicados em cursos superiores em EAD, bem como seus conteúdos e formas de tutoria e mediação, ou mesmo os aspectos financeiros, são superados em termos de resiliência quanto à gestão de vida desses sujeitos. Entendeu-se que os estudantes de $\mathrm{EaD}$ possuem características plurais (CATAPAN et al, 2010). Este reúne aspectos que transitam entre vida cotidiana e a do trabalho, combinando-se com a gestão do tempo e formas de dedicação aos estudos. Nessa mescla, podem ser acentuadas em seus perfis características ora mais racionais, ora mais intelectuais, ou mais afetivas.

Os alunos avaliam muito positivamente a sua trajetória em EaD, de forma que praticamente $100 \%$ dos entrevistados a recomendam e oferecem motivos consistentes para isso. Contudo, simultaneamente a esta afirmação, ainda aparecem posições discrepantes sobre esta forma de recomendação, o que remonta a uma reintrepretação da resposta bastante positiva, buscando-se conhecer mais a realidade desses sujeitos em termos de outras trajetórias pessoais de aprendizagem.

\section{Referências}

CATAPAN, Araci Hack, (2010), Mediação pedagógica diferenciada. In: ALONSO, Katia M.; RODRIGUES, Rosangela S.;BARBOSA, Joaquim G. In Educação a distância: práticas, reflexões e cenário plurais. Cuiabá: Ed. UFMT, 2010.

KENSKI, Vani. Educação e tecnologias: o novo ritmo da informação. 8 ed. Campinas: Papirus, 2012.

MINISTÉRIO DA EDUCAÇÃO. Decreto Federal no. 5.622, de 20.12.2005. Regulamenta o art. 80 da Lei no. 9.394, de 20 de dezembro de 1996, que estabelece as diretrizes e bases da educação nacional. Disponível em: http://www.planalto.gov.br/ccivil_03/_Ato2004-0006/2005/Decreto/D5622.htm. Acesso em: $16 / 04 / 18$

MINISTÉRIO DA EDUCAÇÃO. Lei Federal no. 9.394, de 20.12.1996. Estabelece as diretrizes e bases da educação nacional. Disponível em: http://www.planalto.gov.br/ccivil_03/LEIS/I9394.htm. Acesso em 18/04/2018. 
MINISTÉRIO DA EDUCAÇÃO - Portal do MEC. Atualizada legislação que regulamenta Educação a Distância no país, maio/ 2017. Disponível em http://portal.mec.gov.br/busca-geral/212-noticias/educacao-superior-1690610854/49321mec-atualiza-legislacao-que-regulamenta-educacao-a-distancia-no-pais. Acesso em 19/04/2018.

OLIVEIRA, Alexandro P.; CAVALCANTE, Ilane F.; GONÇALVES, Rousiêne S. O processo de evasão (ou desistência) no curso de licenciatura em letras espanhol ofertado pelo campus ead-ifrn: causas possíveis, In SIED, 2012. Disponível em: http://sistemas3.sead.ufscar.br/ojs/index.php/sied/article/view/236. Acesso em: 22/04/2018.

REIS, Márcia. EAD como Instrumento de inclusão social São Paulo - SP. In Anais do CIEAD, $2015 . \quad$ Disponível em: http://www.abed.org.br/congresso2015/anais/pdf/BD_335.pdf. Acesso em 01/05/2018.

[1] Instituto Nacional de Estudos e Pesquisas Educacionais

[2] AVA- Ambiente Virtual de Aprendizagem

[3] Os respondentes poderiam escolher mais de uma alternativa.

[4] A pergunta já antecipa uma condição de dificuldades em fazer um curso de gradução via $E A D$, principalmente por assumir que sempre existe alguma forma de dificuldade na aprendizagem, independentemente do modelo educacional adotado.

[5] Os respondentes poderiam escolher mais de uma alternativa.

[6] Os repondentes poderiam escolher mais de uma alternativa. 